\title{
Reducing temperature, drag load, and wear during aircraft tyre spin-up
}

\begin{abstract}
Purpose- Due to the static condition of the wheels at touchdown, they skid on the runway, which may cause the tyres to burn and wear. This phenomenon occurs in a fraction of a second known as the spin-up period. The purpose of this paper is to introduce a new strategy to reduce the horizontal force, tyre temperature and wear during the spin-up period. Design/methodology/approach- Firstly, the dynamics of two different phases of landing, namely spin-up and breaking phases, are reviewed. Secondly, a strategy to prevent excessive temperature and wear of the tyre is presented. Findings- It is found that utilizing a lubricant and coolant, such as water, at the spin-up stretch of the runway is a simple and practical solution to prevent excessive temperature and wear of the tyre. It is revealed that, despite increasing the spin-up period, the rise of the tyre temperature is eliminated, and the material properties are preserved for effective braking. A rough quantitative analysis demonstrates that the wetting of tyres in the spin-up phase decreases the loads and tyre wear effectively.
\end{abstract}

Practical implications- Wetting the touchdown region of the runway without significant areas of standing water is the most practical strategy with the technology available today.

Originality/value- A new strategy is presented for landing with reduced tyre wear. It is our hope that this paper can inspire continuous efforts to realize the implementation of the strategy.

Keywords: Aircraft landing; spin-up; touchdown; tyre wear, tyre burn, wet runway. 


\section{Introduction}

The landing phase is the most critical phase of the flight envelope of an aircraft due to the harsh transition from airborne phase to ground rolling. The landing phase from first touchdown to complete stop of a passenger aircraft takes about $30 \mathrm{sec}$ and consists of two different stages. The first stage occurs in a fraction of second (Padovan et al., 1991), where the skidding of the landing wheels changes to fully rolling motion. This period of time is known as spin-up stage or period. The second stage starts from deploying the spoilers, where the weight of the aircraft is transferred gradually to the landing wheels, and subsequently the brakes are activated until the aircraft stop.

Many papers and reports in the field are related to the second stage, where the brakes are activated. However, few articles are devoted to the touchdown dynamics, traction forces, loss of tyres, and temperature control during the spinup period. The only method that has been proposed for preventing excessive tyre wear at landing is the pre-rotation of the wheels, which is not currently used in aircraft.

This paper starts with a review of the current knowledge of the two stages of the landing phase (Sections 2.1 and 2.2). These Sections also form a motivation for the proposed strategy, presented in Section 3. The paper ends with the conclusions drawn while proposing future research directions in Section 4.

\section{Review of the tyre wear characteristics during aircraft landing}

In the following, the spin-up stage and the braking stage are discussed separately.

\subsection{Spin-up stage}

Before touchdown of aircraft, the wheels are stationary. Therefore, due to the high approaching speed of heavy aircraft, an abrasive skidding between the aircraft tyres and the runway surfaces occurs immediately after touchdown. In a fraction of second the skidding changes to fully rolling motion as the wheels accelerate to match the forward speed of the aircraft. Although an important part of the tyre wear may relate to braking and the cornering required during the roll-out and taxi phases (McCurty, 1972), the runway rubber deposits, however, confirm that burn and wear occur in the touchdown and spin-up phases (Bennett et al., 2011). During the spin-up phase, the skidding of the tyres generates enough heat to burn the tyres and may cause the contact patch of the tyre to revert to its uncured state (Wu et al., 2019). This reverted rubber cannot be cooled in the short spin-up time (Linke et al., 2014), hence the directional control of the aircraft or its braking performance during the second phase can be affected by the temperature of the 
tyres (Rosu et al., 2016; Rosu et al., 2018). Therefore, we conclude that, during the spin-up period, preventing the increase of tyre temperature is more important than reducing their wear.

A limited number of articles have examined the spin-up dynamics and few experiments have been performed in this regard. Milwitzky et al. (1955) experimentally investigated the vertical and horizontal ground loads and variations of the coefficient of friction between the tyre and the runway during the wheel spin-up period. Their experiments included three major phases: forward speed tests at horizontal velocity up to $86 \mathrm{ft} / \mathrm{sec}$, forward speed tests with reverse wheel rotation to simulate horizontal velocities up to about $273 \mathrm{ft} / \mathrm{sec}$, and spin-up drop tests. They also examined the effects of the relative velocity of the tyre and runway on the induced forces. Fig. 1a shows the effect of the pre-rotation, ranging from no pre-rotation up to almost complete pre-rotation, on the landing loads during spin-up time. In this figure, $V_{\mathrm{vo}}, V_{\mathrm{car}}, F_{\mathrm{HT}}$, and $F_{\mathrm{VT}}$ are the sink rate, horizontal velocity of carriage, horizontal, and vertical loads between the tyre and ground, respectively. The figure shows that increasing the amount of pre-rotation decreases the spin-up time and reduces the maximum horizontal forces significantly. However, the vertical impact load will not be affected by the pre-rotational speed. Milwitzky et al. (1955) also plotted the maximum horizontal load at three sink rates against the percentage pre-rotation. Their results are shown in Fig. 1b, which demonstrates that the pre-rotation produced a significant reduction in drag load at the higher sink rates.

Furthermore, Milwitzky et al. (1955) concluded that the coefficient of friction was influenced by the skidding velocity and slip ratio. They also claimed that the tyre temperature and the contaminated runway (by abraded rubber) could affect the drag load and friction coefficient. However, these claims were not proven. They stated that at very high approach speeds, the spin-up drag loads may be of the same order as, or even less than, the drag loads caused by other design conditions. Thus, the practical advantages of pre-rotation were not as great as initially thought. 


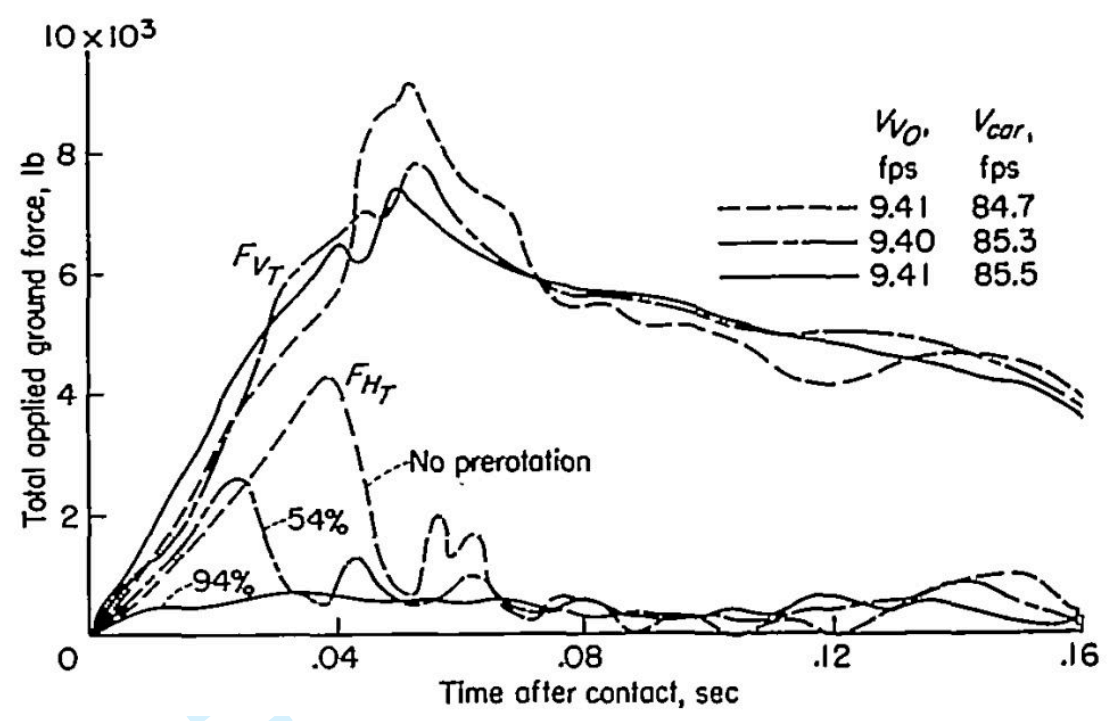

(a)

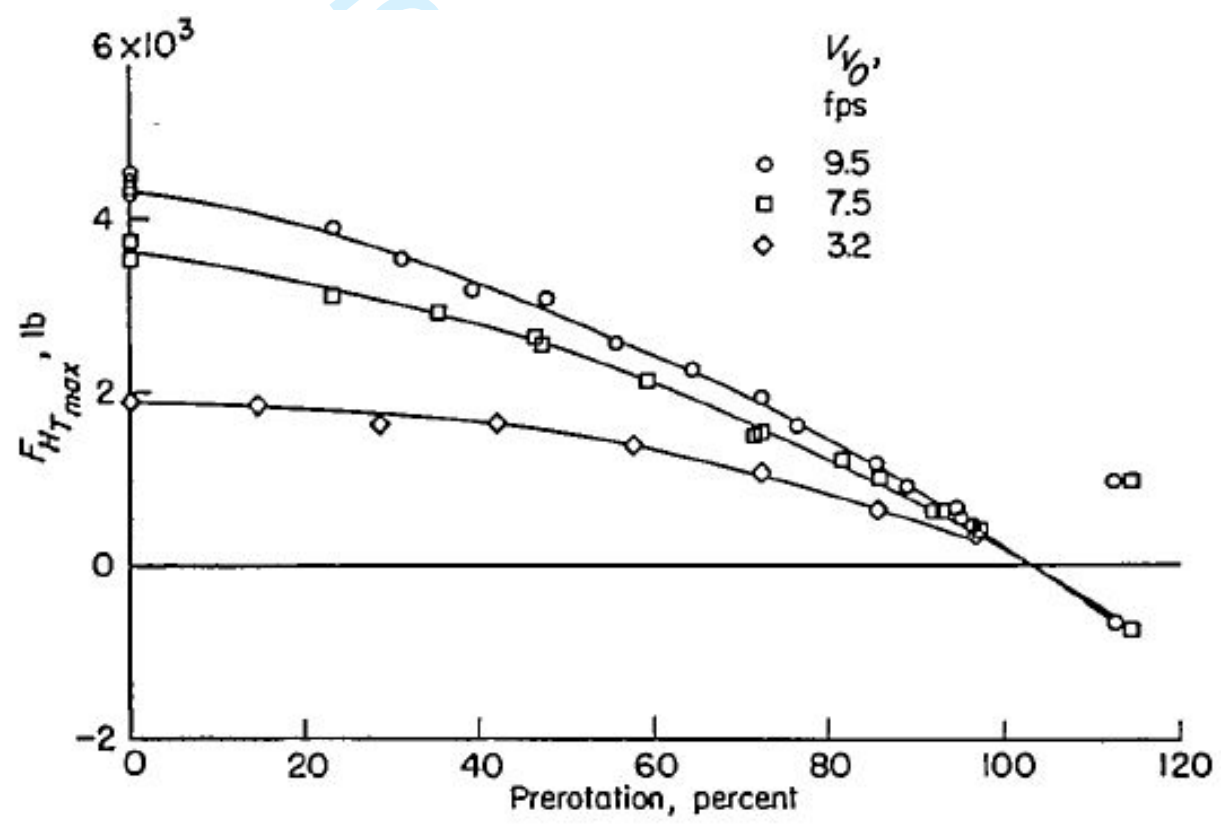

(b)

Fig. 1 Effects of the wheel pre-rotation on the tyre-runway horizontal and vertical loads, a) Time histories of the horizontal and vertical loads, b) Maximum horizontal or drag load, (Milwitzky et al., 1955). 


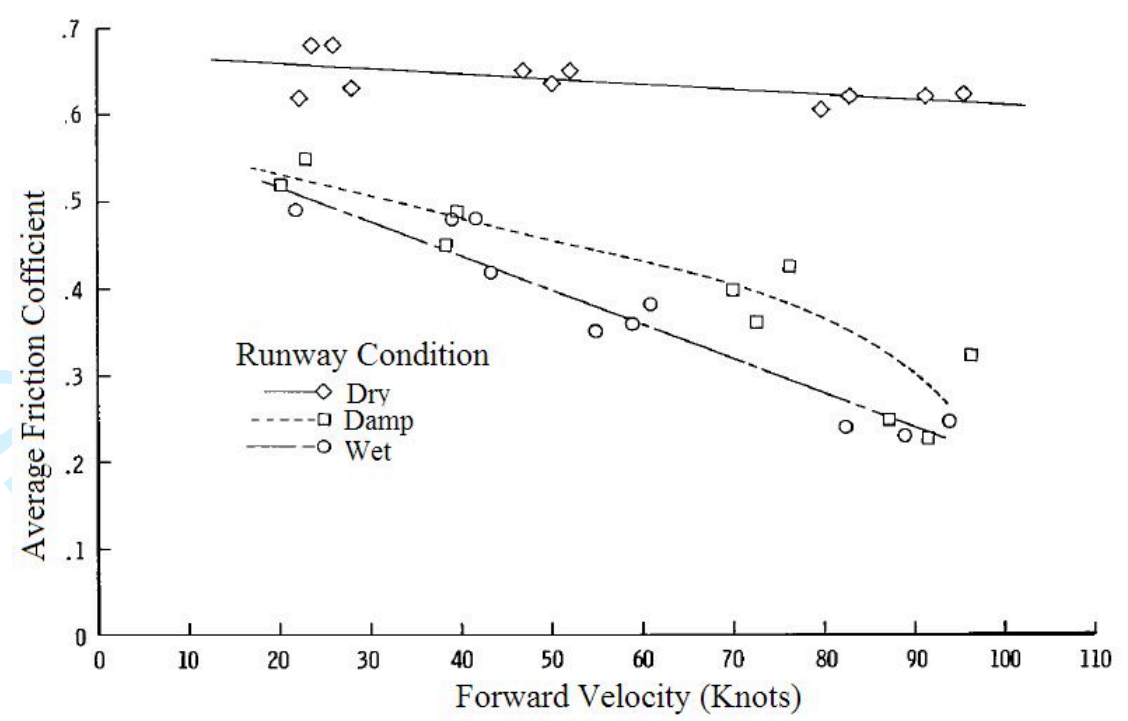

(a)

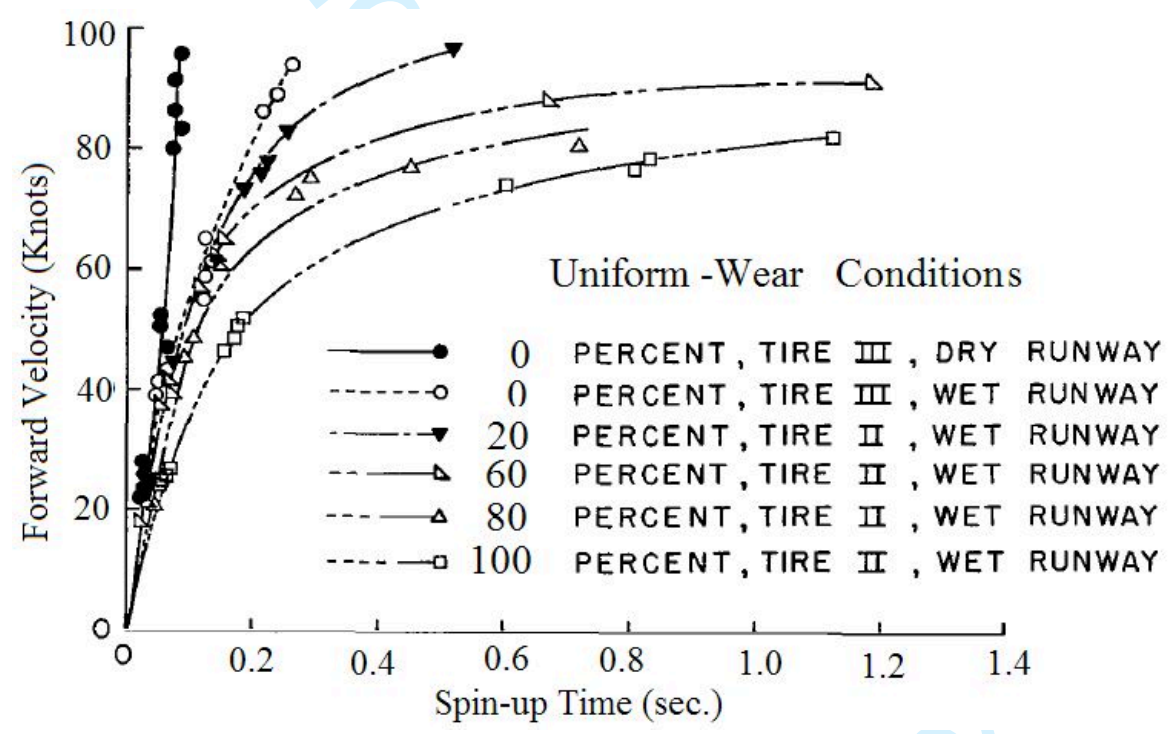

(b)

Fig. 2 a)Effects of runway surface condition on the breaking effectiveness, b) Effects of the tyre wear and wet runway on tyre spin-up time, (Trafford et al., 1965).

In a series of valuable experiments at Langley Research Center, effects of the wet- runway on the variations of the friction coefficient were studied (Trafford et al., 1965). They showed that the presence of small amount of water on the runway surface has a significant effect on the friction coefficient. Fig. 2a depicts the variations of the friction coefficient versus the relative velocity in damp and wet surfaces. In another test, with the brakes released, they 
investigated the spin-up time in wet and dry runways (Fig. 2b). They showed that wetting of the runway increases the spin-up time more than twice at the higher velocities. In addition, the loss of the tyre tread and its wear can have a significant effect on the spin-up distance. The results indicated that the worn-out percentage of a tyre is more important than the wetness of the runway surface. It is worth nothing that the laboratory conditions were not in the speed range of the current heavy passenger aircraft. However, the results in Fig. $2 \mathrm{~b}$ will be important for clarifying our new idea in the next section.

An experimental investigation of the space shuttle orbiter main gear tyre spin-up processes has been conducted at the NASA Langley research center (Daugherty et al., 1988). Effect of the pre-rotation on the spin-up wear was also reported. The influence of forward speed of the space shuttle, as well as its sink rate, on the tyre spin-up ground forces were evaluated. In addition, the effects of the runway characteristics on spin-up time and induced loads were discussed. Figure 3 shows that with decreasing friction coefficient from 0.7 to 0.3 , the horizontal force decreases from $120 \mathrm{KN}$ to $60 \mathrm{KN}$, and the spin-up time increases from 0.1 to $0.25 \mathrm{sec}$. It is revealed that while the increasing spin-up time, or distance, is very small compared to the total length of the runway, the reduction of the tyre contact drag force is significant.

Another experimental study was conducted to compare the spin-up behavior of an aircraft tyre during touchdown on grooved surface with the corresponding behavior on the similar smooth surfaces (McCarty, 1971). It was found that the grooving of a runway surface generally reduces wheel spin-up period. However, the grooving did not appreciably affect the maximum wheel spin-up drag forces. Hence, the spin-up period is decreased without the drag forces being larger, which is surprising since it is in contradiction with the results obtained by Daugherty et al. (1988), who demonstrated that reducing the spin-up time is equivalent to increasing the angular acceleration of the landing wheels, which is the result of increasing the torque or drag force applied to the wheels. 

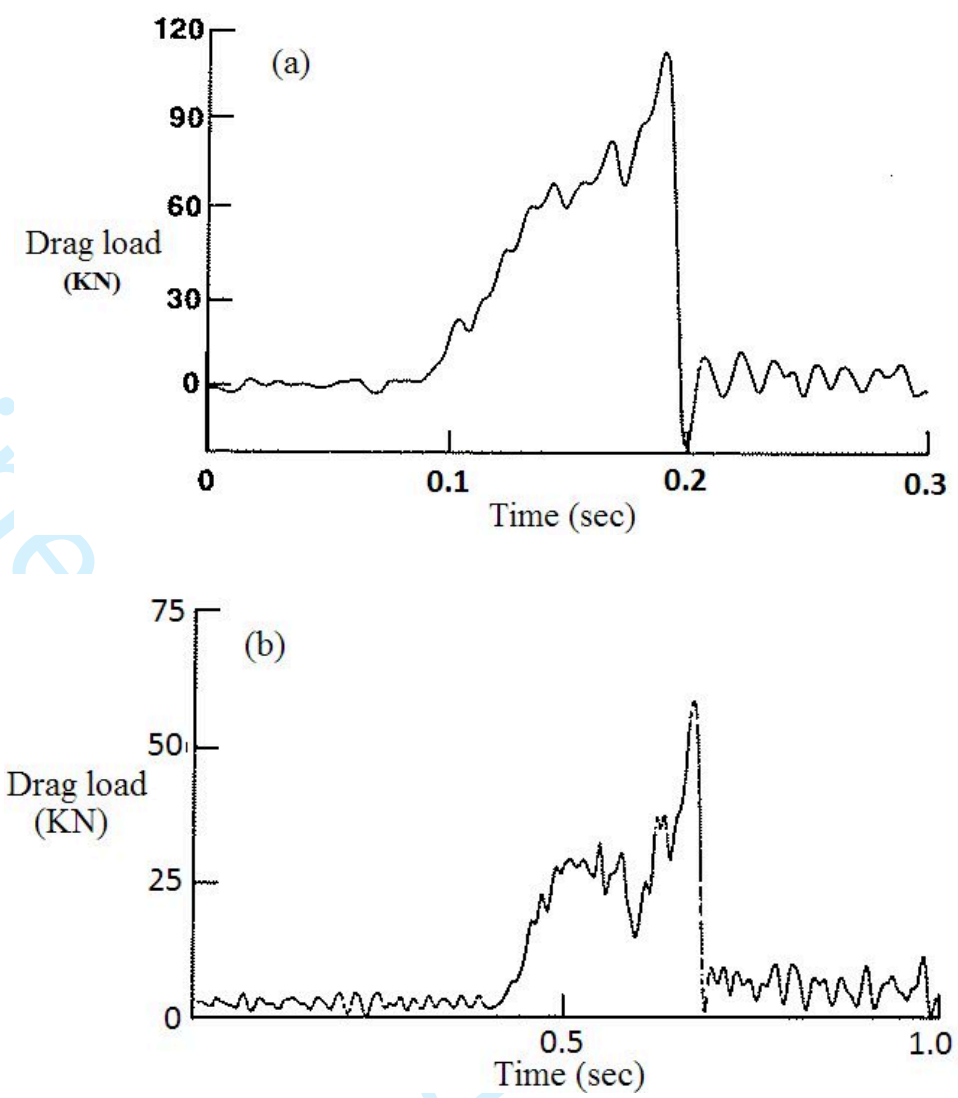

Fig. 3 Ground drag loads for different runway surfaces, a) grooved runway with friction coefficient $0.7, b$ ) grooved runway with friction coefficient 0.3 (Daugherty et al., 1988). Printed with permission from SAE International.

Experimental results and field observations have revealed that during spin-up time, the aircraft tyre burns, its frictional characteristics change effectively, and significant asymmetric wear occurs. Hence, mathematical or even numerical modeling of the spin-up tyre-runway contact dynamics would be very complex. Therefore, only a small number of articles have been published on the modeling of spin-up dynamics, where each of them has its own limitations. For instance, Padovan et al. (1991) developed a tyre spin-up dynamic model and studied the effects of sink rate, runway friction, and aircraft landing speed on the spin-up time. Their case study involved the shuttle main tyres data. Variations of the spin-up time as a function of friction coefficient and sink rate are depicted in Fig. 4. It should be pointed out that the coefficient of friction and wear mechanism are highly affected by the slip ratio and tyre temperature (Waddad et. al., 2019), which were not taken into account by Padovan et al. (1991). 


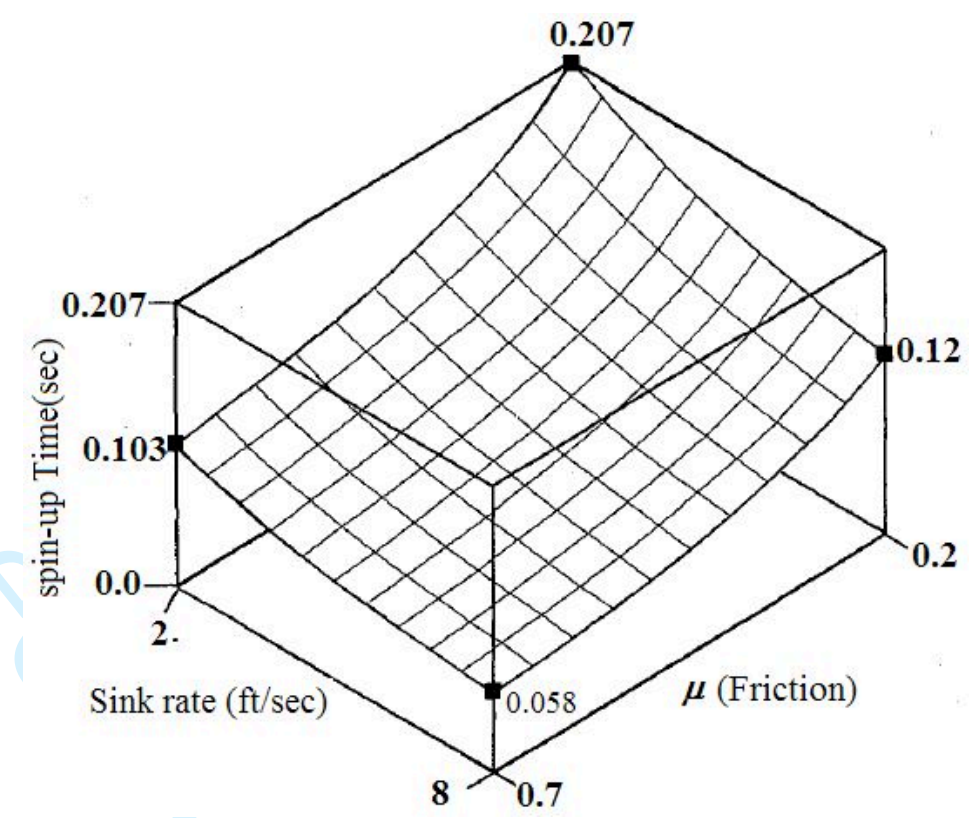

Fig. 4 Parametric effects of sink rate and friction coefficient on the skidding distance or spin-up time (Padovan et al., 1991). Reproduced with permission from AIAA.

Although researchers (Milwitzky et al., 1955) early concluded that the pre-rotation may not be very important for reducing the tyre wear, the reduction of tyre temperature and drag forces are not negligible. Alroqi et al. (2015) studied the effects of the pre-rotation of the landing wheels on the tyre wear. They used a simple single degree of freedom dynamic model and showed that the pre-rotation of the wheels could reduce the abrasive skidding between the aircraft tyre and runway surfaces immediately after touchdown. In their work, the simple Archard wear theory was used to calculate tyre wear. However, due to very complex and nonlinear processes at the touchdown moment with sharp changes in the tyre temperature, calculating tyre wear without considering the tyre temperature and its tyre burning effects may not be reliable.

Alroqi et al., (2017) also employed the commercial software ANSYS for modeling the touchdown process. They utilized a coupled structural- thermal transient analysis to examine the wheel's dynamic response and tyre tread temperature during spin-up period. The tyre tread temperature was calculated for both the initially static and prerotation wheels to show the effectiveness of the pre-rotation. However, they ignored the occasional abrasion of the tyre that may lead to cooling as the hot top layer of the rubber is removed (Linke et al., 2014). Alroqi et al., (2017) claimed that $90 \%$ of the thermal energy generated by the tyre skidding on the runway is transmitted to the tyre and only $10 \%$ goes to the runway. It should be pointed out that the thermal partition coefficients of two contact bodies are 
highly dominated by their thermal conductivities. In other words, the higher the body thermal conductivity, the greater the amount of heat energy transferred to it (Waddad et. al., 2019). Experimental findings showed that the thermal conductivity of the asphalt concrete ranged from 1.7 to $2.1 \mathrm{~W} / \mathrm{m} \cdot{ }^{\circ} \mathrm{C}$ (Mrawira, et al., 2006) and for tire tread or natural rubber is about $0.2 \mathrm{~W} / \mathrm{m}^{\circ}{ }^{\circ} \mathrm{C}$ ( Gschwandl, et al. 2019). Therefore, taking into account the thermal conductivity of the rubber, which is much lower than the asphalt or concrete, Alroqi et al., (2017) assumption seems contradictory. Fig. 5 shows the tyre tread temperature variations in static and pre-rotated wheels from Alroqi et al. (2017). They claimed that the pre-rotation can prevent the tyre heat build-up. They also reported the wheel angular velocities with and without pre-rotation, see Fig. 6. The figure (lowest panel in Fig. 6) clearly indicates that the angular velocity of the wheel at $100 \%$ pre-rotation is oscillating widely. It should be emphasized that such severe rotational speed fluctuations at the moment of contact are not justified and have not been shown in any experimental tests (Daugherty et al., 1988; Besselink, 2000). By referring to the 100\% pre-rotation case (Fig. 6), it is observed that in an interval of about 0.002 second, the wheel angular velocity has decreased from 120 to $30 \mathrm{rad} / \mathrm{sec}$. This velocity reduction is equivalent to a negative angular acceleration of about $45,000 \mathrm{rad} / \mathrm{s}^{2}$. Therefore, according to the radius and rotary inertia of the wheel, a negative horizontal force about 250 tons must be created at the touchdown moment. However, referring to the contact forces reported, such huge horizontal force is unlikely to occur.

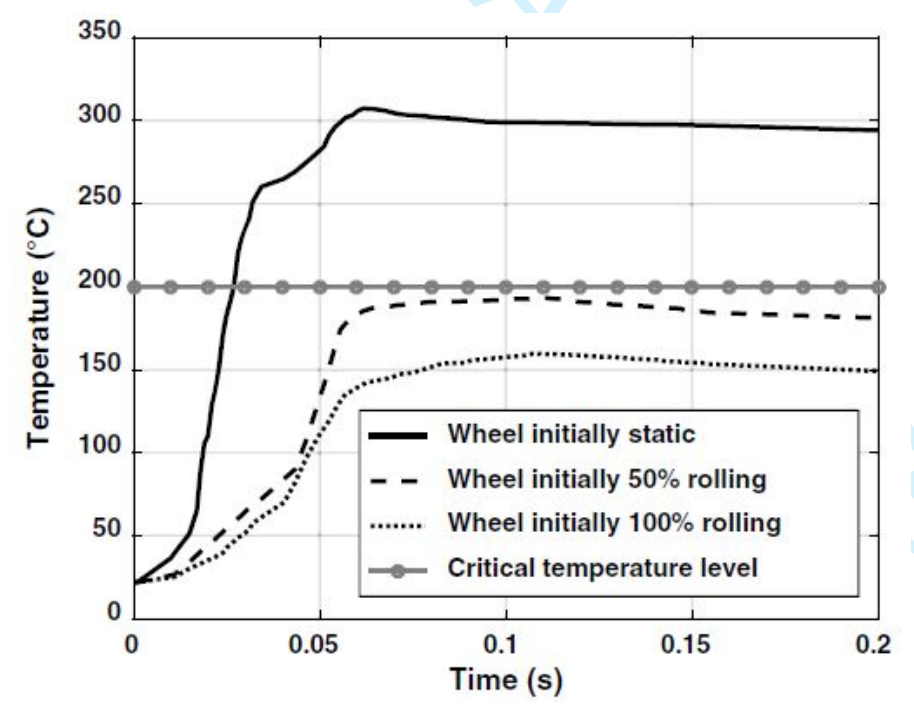

Fig. 5 Variation of the tyre tread temperature for initially static, 50\% pre-rotated wheel, and $100 \%$ pre-rotated wheel (Alroqi et al., 2017). Printed with permission from AIAA. 


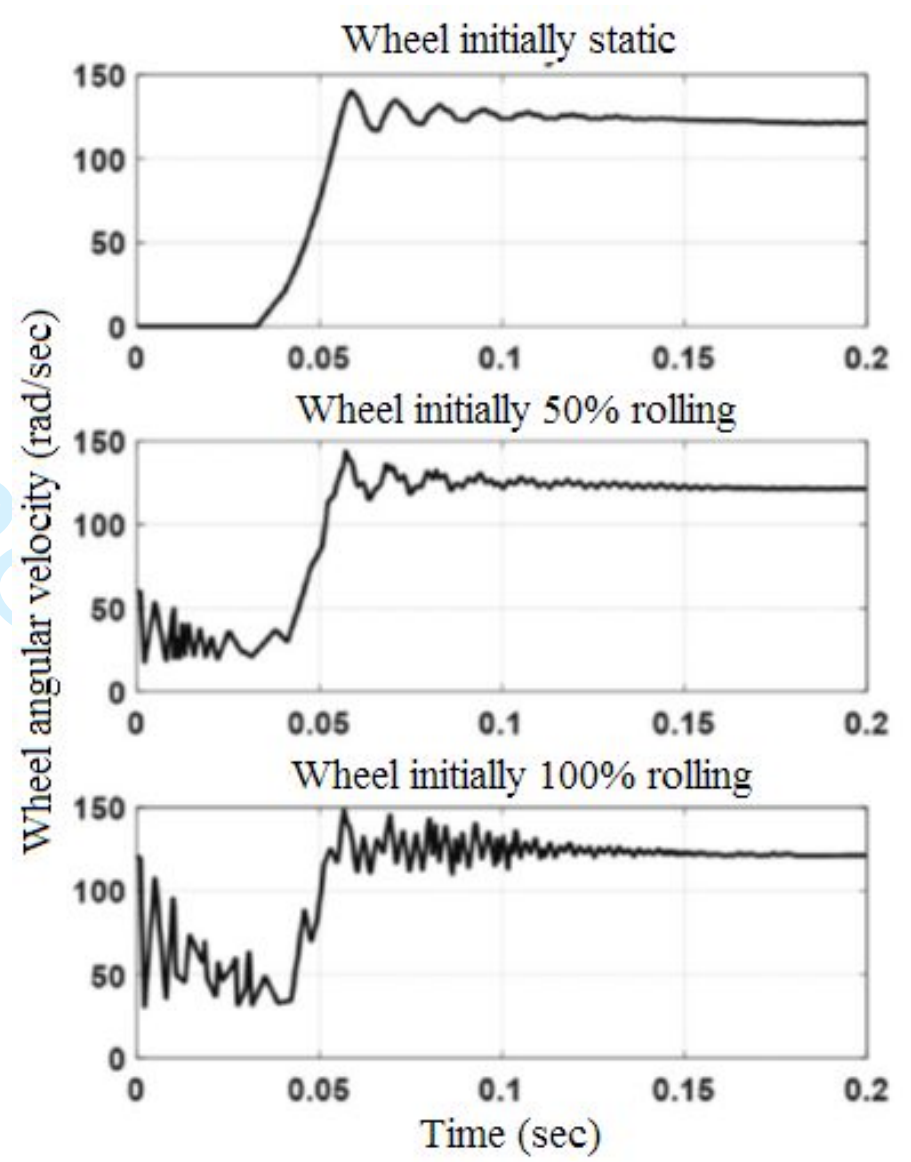

Fig. 6 Variations of wheel angular velocities for initially static, $50 \%$ and $100 \%$ pre-rotated wheel (Alroqi et al., 2017). Printed with permission from AIAA.

In addition to scientific reports and articles related to pre-rotation of the landing wheels, many patents have suggested different mechanisms for pre-rotation of the landing wheels (Beazley, 1947; Robert, 1973; Horvath et al., 2006; Cassetta et al., 2008; Abbasszadeh et al., 2015; Sweet et al., 2014; Karl, 2014; Didey, 2014). However, none of the methods suggested have been implemented on commercial aircraft, as far as the authors know. It seems that, despite some advantages of the pre-rotation system, crucial negative points such as complicating the landing gear mechanism, controllability of the wheels speed in different wind conditions, and imposing additional weight have prevented the use of the pre-rotation system. 


\subsection{Braking stage}

As soon as the spin-up phase is completed and the speed of the wheels has reached their ground synchronous value, the spoilers will be deployed. Consequently, in addition to the weight of the aircraft, more downward aerodynamic force is imposed on the landing wheels. Subsequently, after a delay of 1 to 3 seconds (to ensure complete transferring of the aircraft weight on wheels) the brakes are activated. During the transferring of the vertical load on the landing wheels and in the braking phase (ground operation), the presence of enough friction force between the wheels and runway surface is essential for stability and directional control of the aircraft. The magnitude of the available friction force (or the friction coefficient) is influenced by a large number of factors associated with the aircraft, e.g., aircraft tyre condition, braking system, the runway surface condition, and environmental conditions (Yager, 1983; Horne et al., 1968). Only the runway surface condition is considered in this review.

The tyre tread and its material, together with the runway texture, can play an effective role for the resulting friction coefficient (Horne et al., 1962; Trafford et al., 1965). On the other hand, a wet runway or a runway contaminated by standing water, snow, slush or ice, can have a significant impact on the friction coefficient and deceleration performance during breaking.

It was shown that peak friction coefficient on dry runway surfaces is insensitive to changes in forward velocity of the aircraft (Trafford et al., 1965; Van Es et al., 2001). However, peak tyre-runway friction coefficient developed during braking on contaminated runway surfaces tend to decrease rapidly with increasing forward velocity, see Fig. 2a.

Test results published by Agrawal (1986) revealed that the reduction of the friction coefficient due to braking on the wet runway is attributed to the dynamic, viscose, and/or reverted rubber hydroplaning. For complete dynamic hydroplaning (where the water lifts the tyre completely off the surface), the runway must be flooded beyond a critical fluid depth, and the aircraft velocity in excess of a critical ground speed. However, viscose hydroplaning requires only a thin fluid film to be presented on a smooth runway. This type of hydroplaning can occur at much lower ground speeds than dynamic hydroplaning. Fortunately, the texture existing on most runway surfaces is sufficient to break up and dissipate the thin viscous film which leads to this type of hydroplaning (Horne et al., 1968). The occurrence of different hydroplaning as a function of aircraft speed and water depth has been reported by Agrawal (1986).

On the other hand, studies of heavy braking on wet runway that results in a prolonged locked-wheel skid have disclosed a significant number of cases that could not be fully explained by either the dynamic or the viscous types of 
hydroplaning. In this case, the tyre skidding generates enough heat to cause the rubber in contact with the runway to revert to its original uncured state (Horne et al., 1968). The reverted rubber acts as a seal between the tyre and the runway, and delays water exit from the tyre footprint area. The water heats and is converted to steam which supports the tyre off the runway. This phenomenon is known as reverted rubber hydroplaning.

All of the mentioned hydroplaning can create significantly loss of the tyre traction on the fluid covered runway. It was shown (Horne et al., 1968; Agrawal, 1986; Van Es et al., 2001) that besides the variations of the tyre inflation pressure, aircraft speed, and runway texture, the pavement grooving could be an effective method for alleviating all forms of the tyre traction loss on wet runways. Some valuable experiments related to the different types of hydroplaning and braking performance of an aircraft have been done in Langley Research Center (Horne et al., 1968). In addition, Agrawal (1986) published a comprehensive review paper related to the braking performance of aircraft on wet runways. He discussed a variety of phenomena that lead to aircraft hydroplaning, overruns, and loss of directional control during ground operation and braking phase. He explained that, in addition the grooving of the runway, modern brake systems incorporate highly effective antilock devices can improve braking performance and increase the stability and directional control of the system.

\section{The proposed strategy}

For clarifying the new idea, it is necessary to review the landing sequences in detail. First touchdown of the main wheels with runway surface take places with horizontal velocity about 60 to $90 \mathrm{~m} / \mathrm{sec}$. Due to the static condition of the wheels, at first, the wheels skid on the runway and during a short period of time $(0.1$ to $0.2 \mathrm{sec})$ the slip ratio changes from one to zero (Besselink, 2000; Daugherty et al., 1986). Thus, the abrasive skidding causes the tyres to burn and smoke. Fig. 7 shows the wheel angular velocity recording during the spin-up period.

During this period the aircraft is still in flight-mode where the aerodynamic forces are dominating, and the traction or wheel contact forces act as undesirable system disturbances. Therefore, the brakes must not be activated during this period, otherwise the wheels will lock and skid again. Hence, in contrast to the braking period, where the friction forces between the wheels and the runway surface are crucial for the directional control and the stability, these forces should be as low as possible in the spin-up period to prevent the increased tyre temperature, horizontal shocks, and tyre wear. 


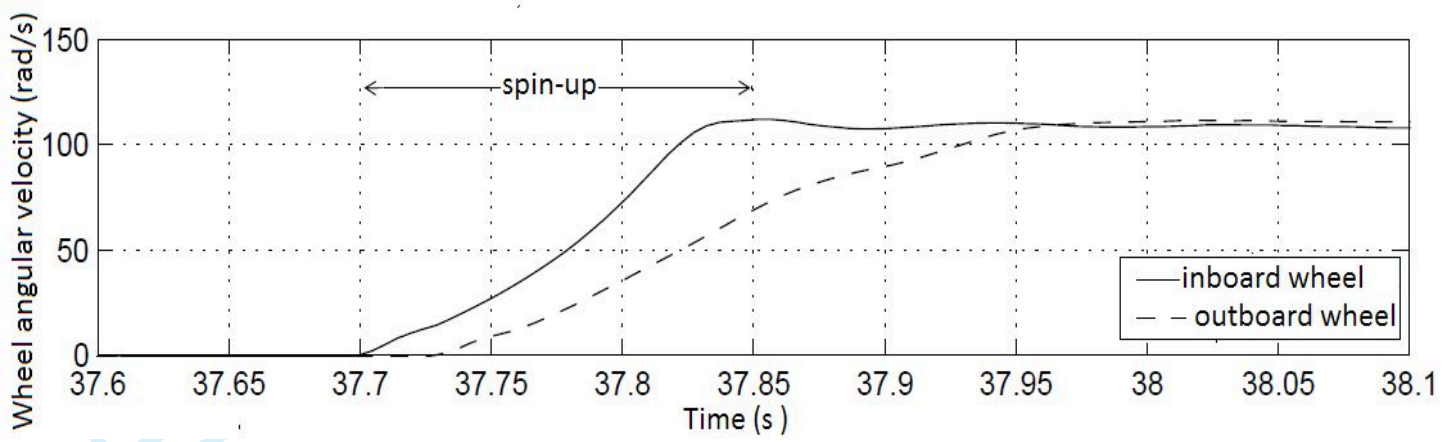

Fig. 7 Variation of the wheel angular velocity during spin-up period (Besselink, 2000). Printed with permission from the author.

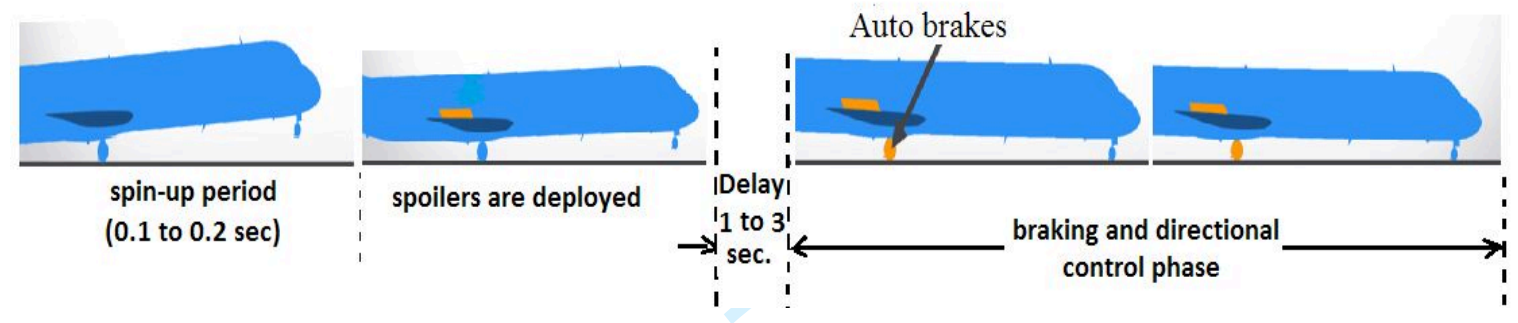

Fig. 8 Stopping sequences of an aircraft after touchdown.

Just after the spin-up period, the spoilers are deployed and after a delay of 1 to 3 seconds the brakes are activated (see Fig. 8). During the breaking phase, unlike the spin-up period, presence of the enough friction force between the wheels and runway surface is essential. Hence, to alleviate tyre traction loss especially on wet runways and prevent hydroplaning, transverse grooving of the runways has been proposed (Horne et al., 1968). However, despite the wet runways in most rainy cities and the lack of grooves on the runway surfaces, the aircraft still make a safe landing on wet runways without significant areas of standing water.

Due to skidding of the tyres during the spin-up, part of the frictional work increases the angular velocity of the landing wheels, and another part heats the tyres and the runway surface. Due to the significant difference between the heat conductivity of the tyres (about $0.15 \mathrm{w} / \mathrm{m}^{\circ} \mathrm{C}$ ) and the material of runway surface, i.e concrete or asphalt (about 0.8 to $2 \mathrm{w} / \mathrm{m}^{\circ} \mathrm{C}$ ), a greater amount of the generated heat flux is transferred to the runway. However, due to low conductivity of the tyres, thermal energy is concentrated on its surface and increases the temperature up to $350{ }^{\circ} \mathrm{C}$. 
Therefore, according to the decomposition temperature of the tyre material (about $200{ }^{\circ} \mathrm{C}$ according to Mandal et al., 2014), it burns in the contact region, and part of it sticks to the runway surface and another part appears as smoke.

Due to the drastic variation of the landing wheels dynamics and kinematics, and the rapid changes of the mechanical and material properties of the tyres, analytical and numerical modeling of the spin-up dynamics is very complex. Even reconstructing the real spin-up conditions in the laboratory is very complicated (Daugherty et al., 1988). Hence, few reports have been presented, and most suffer from restrictive, and sometimes questionable, heat flux assumptions (Kondé et al., 2013; Alroqi et al., 2017). In the following, an attempt has been made to provide approximate results regarding tyre wear in the spin-up phase. Calculations are provided for Boeing 747 where its specifications and spin-up conditions are depicted in Table 1.

Table 1. System parameters and spin-up conditions

\begin{tabular}{ll}
\hline Properties & Values \\
\hline Tyre diameter, d & $1244.6(\mathrm{~mm})$ \\
Aircraft weight, $M$ & $3 \times 10^{5}(\mathrm{~kg})$ \\
Tyre weight, $m$ & $110(\mathrm{~kg})$ \\
Wheel moment of inertia, $I$ & $46\left(\mathrm{~kg} \cdot \mathrm{m}^{2}\right)$ \\
Tyre grooves depth, $h_{g}$ & $13(\mathrm{~mm})$ \\
Tyre width, $w$ & $482.6(\mathrm{~mm})$ \\
Net tyre width, $w_{n}$ & $380(\mathrm{~mm})$ \\
Tyre mass density, $\rho$ & $1125\left(\mathrm{~kg} / \mathrm{m}^{3}\right)$ \\
Landing speed, $V$ & $80(\mathrm{~m} / \mathrm{s})$ \\
Average friction coefficient, $\mu$ & 0.4 \\
Spin-up period, $t_{s p}$ & $0.15(\mathrm{~s})$ \\
Sink rate, $V_{s}$ & $1.5(\mathrm{~m} / \mathrm{s})$ \\
Sink rate settling time, $t_{s t}$ & $0.25(\mathrm{~s})$ \\
Runway heat conductivity & $1.4\left(\mathrm{w} / \mathrm{m} .{ }^{\circ} \mathrm{C}\right)$ \\
Tyre heat conductivity & $0.15\left(\mathrm{w} / \mathrm{m} .{ }^{\circ} \mathrm{C}\right)$ \\
Tyre specific heat, $C_{t}$ & $2300\left(\mathrm{~J} / \mathrm{kg} .{ }^{\circ} \mathrm{C}\right)$ \\
\hline
\end{tabular}


As a general rule, if the tyre tread has been worn to the base of any groove anywhere on the tyre, it should be replaced. However, in the calculations it is assumed that the wear is uniform, and that the tyre is replaced when $85 \%$ of its treads are worn. Hence, the reduction in tyre weight $m_{t l}-$ or the amount of wear of a new tyre over the entire service life will be:

$$
m_{t l}=\pi d w_{n} h_{g} \rho=18.4 \mathrm{~kg}
$$

The spin-up distance is $L_{s}=V t_{s p}=12 \mathrm{~m}$, where $t_{s p}$ is the spin-up period. Considering the sink rate settling time $t_{s t}$, the average vertical $F_{v}$ and horizontal $F_{H}$ traction forces are:

$$
\begin{aligned}
& F_{v}=\left(\frac{V_{s}}{t_{s t}}\right) M=1.8 \times 10^{6} \mathrm{~N} \\
& F_{H}=F_{v} \mu=7.2 \times 10^{5} \mathrm{~N}
\end{aligned}
$$

From an energy perspective, the average friction work $E_{f}$, rotational wheel energy $E_{r}$, and thermal energy $E_{H}$ can be written as:

$$
\begin{aligned}
& E_{f}=F_{H} V t_{s p}=8.64 \times 10^{6} \mathrm{~J} \\
& E_{r}=\left(\frac{1}{2}\right) I \omega^{2}=6.75 \times 10^{6} \mathrm{~J} \\
& E_{H}=E_{f}-E_{r}=1.89 \times 10^{6} \mathrm{~J}
\end{aligned}
$$

According to the thermal conductivity of the tyre and runway material, it is assumed that the amount of the heat flux through each surface is proportional to the respective conductivity. Therefore, in this study, $90 \%$ of the heat is transported to the runway and only $10 \%$ goes to the tyres. Thus, assuming an average increase in tyre temperature ( $\Delta T)$ of $275^{\circ} \mathrm{C}$, the total mass loss of all 18 tyres in each landing during the spin-up period is

$$
0.1 E_{H}=m_{s l} C_{t} \Delta T \rightarrow m_{s l}=0.3 \mathrm{~kg}
$$

Hence, the mass loss of each tyre in each landing is about $0.0167 \mathrm{~kg}$. Part of this lost material sticks to the runway and the other part appears as smoke. Assuming the replacement of each tyre after 300 landings, the amount of loss of each tyre in the spin-up time and during entire service life will be $0.0167 \times 300=5.0 \mathrm{~kg}$. Consequently, according to the result of Eq. (1), it can be concluded that $27 \%$ of the tyre lost occurs in the spin-up period and $73 \%$ of it relates to the braking, cornering, and taxiing phases. 
The above calculations can be compared to the experimental measurements of Morris (2006), who estimated that a Boeing 747 could lose as much as $0.812 \mathrm{~kg}$ of rubber per landing, on the basis of average weight loss. Thus, each tyre loses $0.045 \mathrm{~kg}$ for each landing according to Morris (2006). Combining with our calculations $(0.0167 \mathrm{~kg}$ in each spin-up period) yields that $37 \%$ of tyre weight loss is related to the spin-up period. The difference in tyre wear percentage (we found $27 \%$ above) may be partially attributed to the different types of tyre damage that Morris referred to as worn tyres. He weighed 45 worn Boeing 747 tyres after 180 landings (with no reference being made to the tread wear), while our estimates are based on that $85 \%$ of treads of all weighed tyres have been worn, corresponding to 300 landings.

Hence, it can be claimed that by controlling the temperature in this period, the consumption of tyres can be reduced effectively. Furthermore, experimental results have also shown that high temperature in braking and taxiing conditions can also increase tyre wear drastically (Wu et al., 2019). Fig. 9 shows the variations of aircraft tyre wear rate versus the tyre temperature. Therefore, controlling the tyre temperature during the spin-up period can significantly reduce tyre wear in the braking and taxiing phases, and also improve the braking performance.

To minimize the tyre wear and temperature increase during the spin-up phase, the friction coefficient between the landing wheels and the runway should be reduced as much as possible. Here, we propose that the part of the runway where the transition occurs (spin-up distance), should be covered with a coolant and lubricant, such as water, see Fig. 10a. The wetting of the interface between tyre and surface can also be performed by injecting the desired antifreeze coolant or lubricant liquid on the tyre surface during the spin-up transition, see Fig. $10 \mathrm{~b}$.

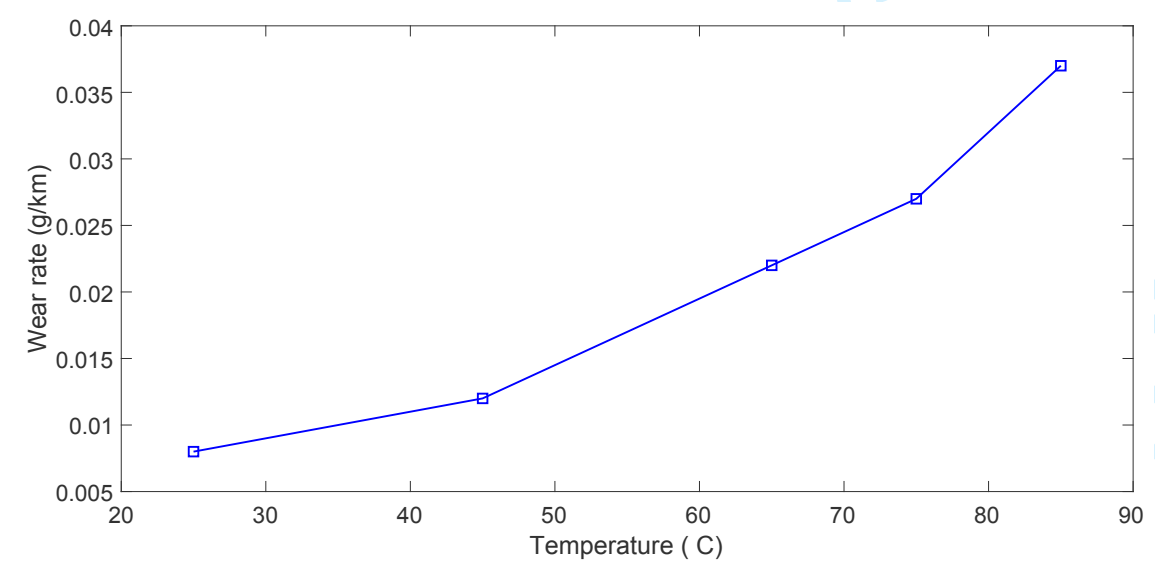

Fig. 9 Experimental variations of aircraft tyre wear rate versus the tyre temperature for slip angle $5^{\circ}(\mathrm{Wu}$ et al., 2019). 


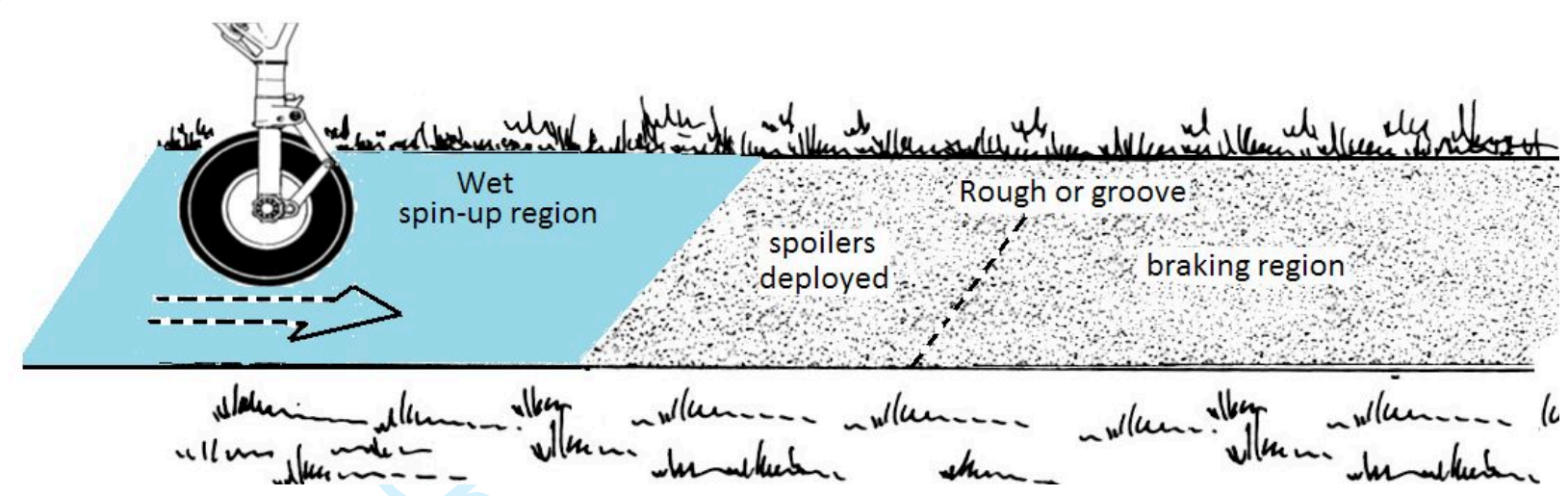

(a)

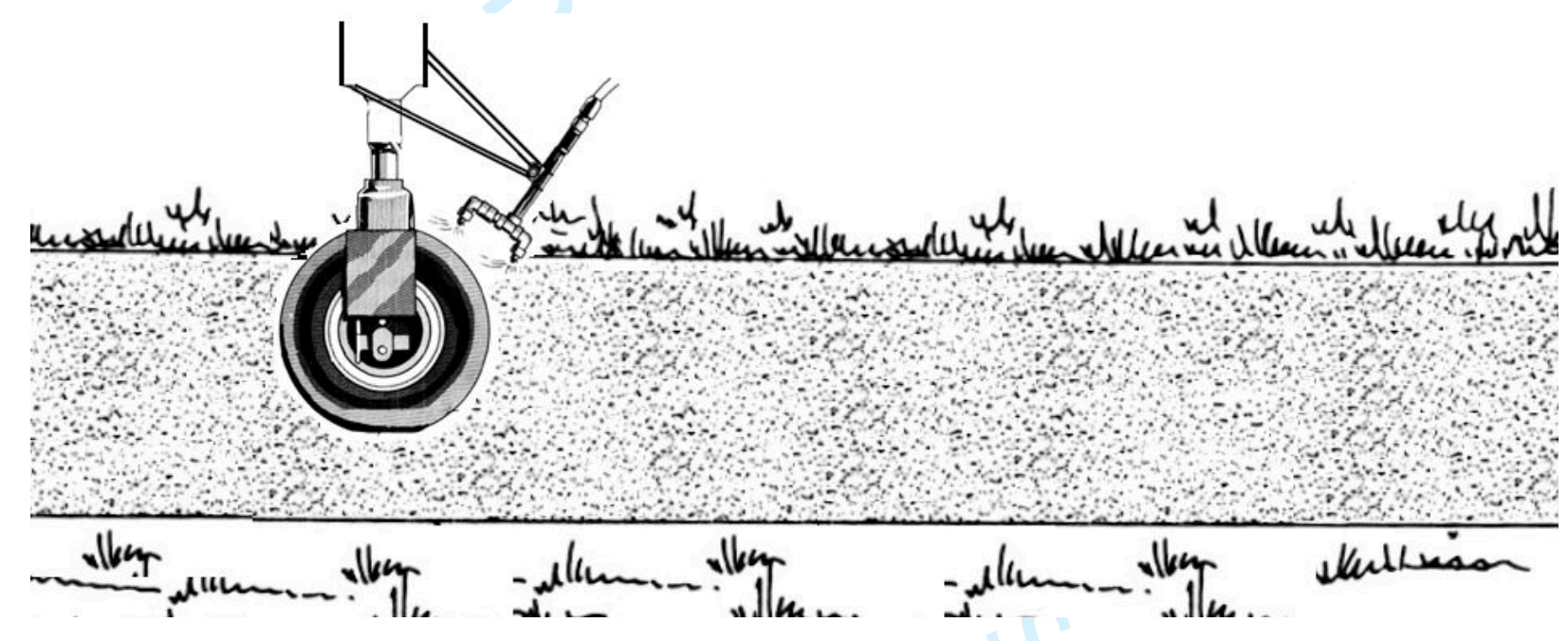

(b)

Fig. 10 Schematic view of the proposed strategy, a) runway with wet spin-up region, b) wetting of the tyre surface with a coolant and lubricant during spin-up period.

Although wetting the touchdown segment of the runway increases the spin-up distance (Fig. 2b), the increment (dozens of meters) will be very small compared to the total runway length. For example, if the friction coefficient decreases from 0.7 to 0.2 (by wetting the spin-up distance), the spin-up time will increase from $0.1 \mathrm{sec}$ to $0.2 \mathrm{sec}$ - see Fig. 4. In other words, the spin-up distance increases from 8 meters to about 15 meters. This means that the landing wheels undergo several revolutions before reaching rolling speed. Therefore, abrasion is not concentrated to a specific part of the tyre surface, but is distributed on the peripheral surface of the tyre. 
Furthermore, reducing coefficient of friction during spin-up reduces the horizontal drag force on the landing wheels, resulting in a significantly increased fatigue life and improved the frequency response of the landing mechanism (Chaudhary, 2021). Reducing the drag load will also improve the touchdown performance and consequently minimize the maximum strut load transmitted to the fuselage (Li et al., 2017). In addition, during this period, the wheels are not completely locked and the slip ratio will change from one to zero. Hence, reverted rubber hydroplaning will not occur (Horne, 1968).

\section{Conclusions}

The spin-up phase is the most critical transition in the landing process. For dry runways, this transition takes place very roughly and causes damage to the tyres and runway surfaces. Hence, we propose to utilize a lubricant and coolant such as water at the spin-up distance to prevent the tyre temperature and wear increment. It should be noted that the coolant effect is more important than the lubricant effect. By controlling the tyre temperature (high temperature shocks), the braking will be done by the tyres with their material properties preserved, in addition to significantly reducing tyre loss during the spin-up phase. Also, with decreasing tyre temperature related to the braking and taxiing phases, the tyre wear in theses phases could be significantly reduced (Wu et al., 2019).

The easiest way to implement the proposed method is to wet the spin-up distance of the runways. Wetting the spin-up zone is very simple and has the following advantages that cannot be ignored.

1. Although an important part of the tyre wear may relate to the braking and cornering phase, wetting of the spin-up distance decreases the tyre wear significantly. However, the proposed idea should be evaluated in an experimental setup or in practical field trials.

2. The friction coefficient and wear of the tyre strongly dependent on the tyre temperature (Linke et al., 2014; Rosu et al., 2016; Wu et al., 2019). Thus, wetting the runway surface at the spin-up distance prevents the tyre temperature from rising. Therefore, the material properties of the tyres are preserved, and consequently the performance of the braking, cornering, and low speed maneuvering will be improved.

3. Wetting the spin-up part of the runway also reduces the friction coefficient and consequently decreases the amount of the horizontal shock or load, resulting in a relatively soft landing which improves the fatigue life of the landing gear and aircraft structure. 
4. The proposed method also prevents the touchdown zone from rubber deposit accumulation. Hence, the concern of environmental pollution due to rubber deposition on the runway and puff of smoke (rubber burning) can also be resolved.

It should be emphasized that airplanes still land safely during rainy conditions (in well soaked runways without significant areas of standing water and cross wind). Hence, wetting the touchdown region of the runway without significant areas of standing water is the simplest, safest, and most practical method with the technology available today. The authors are working on the design of an experimental setup that will clarify the effectiveness of the proposed strategy in the near future. We hope the present paper will inspire others to follow our analytical approach to develop novel solutions to the problem of excessive tyre wear. 


\section{References}

Abbasszadeh, M., T., and Abbasszadeh, M., U.S. Patent Application for a "Apparatus for causing an aircraft wheel to rotate”, Publication No. US20150021435 A1. Washington, DC: U.S.Patent and Trademark Office. 22 Jan 2015.

Agrawal, S.K. (1986). "Braking performance of aircraft tires", Progress in Aerospace Science, Vol. 23, pp.105-150. https://doi.org/10.1016/0376-0421(86)90002-3

Alroqi, A. A., Wang, W., and Zhao, Y. (2017). “Aircraft Tire Temperature at Touchdown with wheel prerotation”, Journal of Aircraft, Vol. 54, No 3, pp. 926-938. https://doi.org/10.2514/1.C033916

Alroqi, A. A., and Wang, W. (2015). "Comparison of Aircraft Tire Wear with Initial Wheel Rotational Speed", International Journal of Aviation, Aeronautics, and Aerospace, Vol.2 No.1, https://doi.org/10.15394/ijaaa.2015.1043

Beazley, R. H., U.S. Patent Application for a “Aircraft wheel spinner and control”, Publication No. US2414849 A. Washington, DC: U.S. Patent and Trademark Office. 28 Jan 1947.

Bennett, M., Christie, S.M., Graham, A., Thomas, B.S., Vishnyakov, V., Morris, K., Peters, D.M., Jones, R., and Ansell, C., (2011). “Composition of Smoke Generated by Landing Aircraft”, Environ. Sci. Technol., Vol. 45, pp.3533-3538. https://doi.org/10.1021/es1027585

Besselink, I.J.M. (2000). Shimmy of aircraft main landing gears. Delft: Technische Universiteit Delft. PhD thesis. https://www.tue.nl/en/publication/ep/p/d/ep-uid/227775/

Cassetta, F. G., and Perez, L. C., U.S. Patent Application for a "Passive acceleration device foraircraft wheels", Publication No. EP1944233 A1. Washington, DC: U.S. Patent and Trademark Office. 16 Jul 2008.

Chaudhary, R., (2021). "Investigation on structural dynamics of landing gear”, Materials Today: Proceedings, Vol.46, No. 1, pp. 9-15. https://doi.org/10.1016/j.matpr.2020.03.324

Daugherty, R.H., and Stubbs, S.M., (1988). "Spin-Up Studies of the Space Shuttle Orbiter Main Gear Tire”, Aerospace Technology Conference and Exposition, Anaheim, California, October 3-6. 
Didey, A., U.S. Patent Application for a "Landing gear drive systems", Publication No.WO2014023939 A1. Washington, DC: U.S. Patent and Trademark Office. 13 Feb 2014.

Gschwandl, M., Kerschbaumer, R.C., Schrittesser, B., Fuchs, P.F., Stieger, S., and Meinhart, L., (2019). “Thermal Conductivity Measurement of Industrial Rubber Compounds using Laser Flash Analysis: Applicability, Comparison and Evaluation”, AIP Conference Proceedings 2065, 030041. https://doi.org/10.1063/1.5088299

Horne, W.B., and Leland, T.J. W. (1962). "Influence of tire tread pattern and runway surface condition on braking friction and rolling resistance of a modern aircraft tire”, Langley Research Center, NASA TN D-1376.

Horne, W.B., Yager, T.J., and Glenn, T.R. (1968). "Review of causes and alleviation of low tire traction on wet runways”, NASA TN D-4406. National Aeronautics and Space Administration. Washington. D.C.

Horvath, V., and Szoke, B., U.S. Patent Application for a "Airplane tire saver by protrusion airfoils", Publication No. WO2006130944 A1. Washington, DC: U.S. Patent and Trademark Office. 14 Dec 2006.

Karl, W., U.S. Patent Application for a "Free Spinning Wheel for Airplanes", Publication No.US20140048648 A1. Washington, DC: U.S. Patent and Trademark Office. 20 Feb 2014.

Kondé, A.K., Rosu, I., Lebon, F., Brardo, O., Devésa, B. (2013). “Thermomechanical analysis of an aircraft tire in cornering using coupled ale and lagrangian formulations", Cent. Eur. J. Eng., Vol.3 No.2, pp.191-205. https://doi.org/10.2478/s13531-012-0049-6

Li, Y., Zheng Jiang, J., Sartor, P., Neild, S.A., Wang, H., (2017). “Including Inerters in Aircraft Landing Gear Shock Strut to Improve the Touch-down Performance", Procedia Engineering, Vol. 199, pp. 1689-1694. https://doi.org/10.1016/j.proeng.2017.09.366

Linke, T., Wangenheim, M., Lind, H., and Ripka, S. (2014). “Experimental Friction and Temperature Investigation on Aircraft Tires", Tire Science and Technology, Vol.42 No.3, pp.116-144. https://doi.org/10.2346/tire.14.420301 
Mandal, A., Pan,S., Mukherjee, S., Saha, A.K., Thomas, S., and Sengupta, A. (2014). "Variations in Specific Heat and Microstructure in Natural Rubber Filled with Different Fillers as Studied by Differential Scanning Calorimetry", Journal of Polymer and Biopolymer Physics Chemistry, Vol.2 No. 1, pp.25-28. http://pubs.sciepub.com/jpbpc/2/1/4

McCurty, J.L., (1972). "Wear and related characteristics of an aircraft tire during braking”, National aeronautics and space administration NASA, Langley research center, Washington, DC.

McCarty, J.L., (1971). “Effects of runway grooving on aircraft tire spin-up behavior”, National aeronautics and space administration NASA, Langley research center technical report TM X-2345.

Milwitzky, B., Lindquist, D. C., \& Potter, D. M. (1955). “An experimental study of applied ground loads in landing”. National advisory committee for aeronautics, Langley aeronautical laboratory, Washington,DC. http://hdl.handle.net/2060/19930092250

Mrawira, D.M., Luca, J., (2006). "Effect of aggregate type, gradation, and compaction level on thermal properties of hot-mix asphalts", Canadian Journal of Civil Engineering, Vol.33, No.11, pp.1410-1417. https://doi.org/ 10.1139/106076

Morris, K., (2006). "An estimation of the tyre material erosion from measurements of aircraft tyre wear", British Airways Environmental Affairs, ENV/KMM/1131/14.18.

http://britishairways.it/cms/global/pdfs/csr/PSDH_Technical_Reports.pdf [accessed 27 June 2016].

Padovan, J., Kazempour, A., and Kim, Y.H., (1991). “Aircraft Landing-Induced Tire Spinup”, Journal of Aircraft, Vol. 28 No.12. https://doi.org/10.2514/3.46108

Robert, A., U.S. Patent Application for a "Self rotating airplane tire", Publication No. US3773283 A. Washington, DC: U.S. Patent and Trademark Office. 20 Nov 1973.

Rosu, I., Elias-Birembaux, H.L., Lebon, F., Lind, H., and Wangenheim, M. (2016). “Experimental and Numerical Simulation of the Dynamic Frictional Contact between an Aircraft Tire Rubber and a Rough Surface", Lubricants, Vol. 4 No.3. https://doi.org/10.3390/lubricants4030029 
Rosu, I., Elias-Birembaux, H.L., Lebon, F., (2018). "Finite element modeling of an aircraft tire rolling on a steel drum: Experimental investigations and numerical simulations”, Applied Science, MDPI, Vol.8, No.4, pp. 593. https://doi.org/10.3390/app8040593

Sweet, R.. M., Gilleran, N., Edelson, J. S., Cox, I. W., Cox, R. T., U.S. Patent Application for a "Integrated electric motor and gear in an aircraft wheel”, Publication No. US8714481 B2.Washington, DC: U.S. Patent and Trademark Office. 6 May 2014.

Trafford, Leland J. W., and Glenn R. T. (1965). “An investigation of the influence of aircraft tire-tread wear on wetrunway braking", NASA TN D-2770.

Van Es, G.W.H., Roelen, A.L.C., Kruijsen, E.A.C., and Giesberts, M.K.H., (2001). "Safety aspects of aircraft performance on wet and contaminated runways", National Aerospace Laboratory NLR, NLR-TP-2001-216.

Waddad, y., Magnier, V., Dufrénoy, P., Saxcé, Ge., (2019). "Heat partition and surface temperature in sliding contact systems of rough surfaces", International Journal of Heat and Mass Transfer, Vol.137, pp. 1167-1182. https://doi.org/10.1016/j.ijheatmasstransfer.2019.04.015

Wu, J., Chen, L., Wang, Y., Su, B., Cui, Z., and Wang, D., (2019). "Effect of temperature on wear performance of aircraft tire tread rubber", Polymer Testing, Vol.79, 106037. https://doi.org/10.1016/j.polymertesting.2019.106037

Yager, T.J. (1983). "Review of factors affecting aircraft wet runway performance", American Institute of Aeronautics and Astronautics. Paper No. AIAA-83-0274. https://doi.org/10.2514/6.1983-274 
2022-02-01

\section{Reducing temperature, drag load and wear during aircraft tyre spin-up}

Mahjouri, Saeed

Emerald

Mahjouri S, Shabani R, Skote M. (2022) Reducing temperature, drag load and wear during aircraft tyre spin-up. Aircraft Engineering and Aerospace Technology, Volume 94, Number 6 , pp. 906-914

https://doi.org/10.1108/AEAT-09-2021-0287

Downloaded from Cranfield Library Services E-Repository 